\title{
Bioindicadores Edáficos de Fragmentos Florestais Urbanos da Cidade de São Paulo (SP)
}

\author{
Edaphic Bioindicators of Urban Forest Fragments in the City of São Paulo (SP)
}

\author{
Natalia Nunes Patucci', Luís Carlos luñes Oliveira Filho², Carlos Batista da Silva ${ }^{3}$, Déborah de Oliveira ${ }^{4}$, Dilmar Baretta ${ }^{5}$ \\ Antonio Domingos Brescovit ${ }^{6}$ \\ 1 Universidade de São Paulo, natalia.oliver@usp.br \\ 2 Universidade do Estado de Santa Catarina, iunes1981@gmail.com \\ 3 Universidade de São Paulo, krlosbatist@gmail.com \\ Recebido (Received): 20/08/2018 \\ 4 Universidade de São Paulo, debolive@usp.br \\ Aceito (Accepted): 01/12/2018 \\ 5 Universidade do Estado de Santa Catarina, dilmarbaretta@gmail.com \\ 6 Instituto Butantan, antonio.brescovit@butantan.gov.br
}

Resumo: A pesquisa avaliou a biodiversidade e qualidade de solos em fragmentos florestais urbanos da cidade de São Paulo (SP), especificamente nos parques Cientec, Cantareira e Jaraguá, utilizando exemplares edáficos como bioindicadores de alteração ambiental. Foram verificadas a diversidade, frequência e riqueza dos indivíduos coletados e suas correlações com alternância de ambientes, estação do ano e atributos químicos como pH, C.O, K, $\mathrm{P}, \mathrm{Ca}, \mathrm{Mg}$ e $\mathrm{Al}$, respeitando a réplica verdadeira dos ambientes $(\mathrm{n}=3)$. Delimitou-se aleatoriamente parcelas amostrais de 1,68 ha onde foram coletados: amostras de solo e invertebrados associados à interface solo serrapilheira por armadilhas de queda (Pitfall-Trap). Foi realizada nas áreas de estudo uma coleta concentrada no verão (02/2014) e inverno (09/2014) ao nível de ambiente (com presença e ausência de drenagem). Foram identificadas famílias e morfo-espécies de aranhas (Araneae) e besouros (Coleoptera). As análises multivariadas demonstraram que existe separação entre os ambientes estudados e quais foram as famílias e morfo-espécies que mais se associaram com cada variável analisada. A redução da acidez, aumento ou diminuição do teor de C.O e Al e a elevada disponibilidade de macronutrientes ( $\mathrm{P}, \mathrm{K}, \mathrm{Ca}$ e $\mathrm{Mg}$ ), foram as variáveis edafo-ambientais que mais preservaram interação com o aumento ou detrimento dos organismos, explicando sua distribuição nos ambientes e estações do ano. $\mathrm{O}$ índice de diversidade de Shannon $(\mathrm{H})$, a riqueza e a diversidade dos organismos coletados foram influenciados pelas variações microclimáticas, cobertura vegetal, qualidade da serapilheira, C.O e macronutrientes. Os organismos se comportaram como indicadores ecológicos sensíveis às alterações edafoambientais na Mata Atlântica.

Keywords: Impactos Ambientais, Solos Urbanos, Aranhas, Besouros.

Abstract: The research evaluated the soil biodiversity and soil quality in urban forest fragments of the city of São Paulo (SP), especially in the Cientec, Cantareira and Jaraguá parks, using edaphic specimens as indicators of environmental change. The variables, $\mathrm{pH}, \mathrm{CO}, \mathrm{K}, \mathrm{P}, \mathrm{Ca}, \mathrm{Mg}$, and $\mathrm{Al}$ were observed, respecting the true replication of the environments $(n=3)$. Sampling plots of 1.68 ha were randomly delineated: soil samples and invertebrates associated to the leaf-littler interface by pitfall traps. In the study areas were carried out collects in summer (02/2014) and winter (09/2014), with presence and absence of drainage Families and morphospecies of spiders (Araneae) and beetles (Coleoptera) were identified. The multivariate analysis showed that there is a separation between the studied environments and which families and morpho-species were most associated with each analyzed variable. The reduction of acidity, increase or decrease of the content of C.O and Al and high availability of macronutrients ( $P, \mathrm{~K}, \mathrm{Ca}$ and $\mathrm{Mg}$ ), were the most environmentally-sensitive variables that preserved interaction with the increase or detriment of organisms, explaining their distribution in environments and seasons. The diversity index of Shannon $(H)$, the richness and diversity of the collected organisms were influenced by microclimatic variations, vegetal cover, quality of litter, C.O and macronutrients. The organisms behaved as ecological indicators sensitive to environmental edaphic changes in the Atlantic Forest

Keywords: Impactos Ambientais, Solos Urbanos, Aranhas, Besouros. 


\section{Introdução}

Organismos bioindicadores de qualidade do solo são comunidades ou grupos cuja diversidade, abundância, função ecológica e ocorrência revelam a possibilidade de alteração ambiental (climáticas, físicas, químicas, biológicas, etc) provocada por influência antrópica ou natural (BARETTA et al., 2010). Os indicadores funcionam como parâmetros de comparação, podendo ser usados para avaliar a biodiversidade e os estágios de degradação, e restauração ambiental dos mais variados ecossistemas (LAVELLE et al., 2006). A qualidade do solo, segundo Vezzani e Mielniczuk (2009), integra comportamentos biológico, físico e químico, e além disso, influencia diretamente na distribuição dos grupos edáficos que ali habitam e desempenham seus serviços ecossistêmicos.

A dinâmica da bioturbação de organismos edáficos realizada pelas minhocas (Oligochaeta), aranhas (Araneae), lacraias (Chilopoda), besouros (Coleoptera), piolhos-de-cobra (Diplopoda) e tatus (Isopoda) também podem interferir, direta ou indiretamente, na permeabilidade, porosidade, morfologia e compactação dos solos devido à construção de galerias, túneis e bioporos o que consequente influencia nas mudanças de estruturas, tornando-as mais granulares e grumosas (PORTILHO et al., 2011;MELO-JÚNIOR, 2012; ROSA et al., 2015).

O papel funcional desempenhado pelos organismos edáficos irá variar de acordo com características da serrapilheira, disponibilidade de alimento, microclima do solo, características químicas e tipos pedológicos (LAVELLE \& PASHANASI, 1989), relações que irão acarretar na diversidade e abundância dos invertebrados. Essas interações poderão ainda auxiliar nos processos físicos, químicos e biológicos dos solos mediante relações ecológicas intraespecíficas que ocorrem nos nichos pedológicos e esferas de influências (BEARE et al., 1995) e, assim, influir na qualidade dos mesmos. No caso de parâmetros físicos, os invertebrados edáficos podem influenciar na agregação e descompactação de solo, aeração, porosidade, percolação e armazenamento de água; nos químicos, os organismos edáficos são agentes na ciclagem de nutrientes e mineralização de resíduos orgânicos e nos biológicos, colaboram com a decomposição e disseminação de esporos (JAMES et al., 2015). Logo, o conhecimento dessas comunidades e suas funções são indispensáveis para a preservação da biodiversidade no solo e seu funcionamento.

Os grupos taxonômicos respondem de formas diferenciadas às alterações do seu habitat, e por isso é indispensável à avaliação integrada de parâmetros ambientais em consonância com as funções ecológicas desempenhadas pelos organismos (LAVELLE et al., 2006). Desde as contribuições de Darwin (1881) já se discutia a importância da função ecológica dos organismos edáficos, especialmente para as minhocas, que desempenhariam a função de arado natural ao ingerir e mover as partículas do solo e resíduos vegetais. O uso dos bioindicadores como ferramenta para mensurar a qualidade de solos vem crescendo a nível mundial, porém se conhece muito pouco sobre as funções ecossistêmicas realizadas pelos invertebrados edáficos (BARETTA et al., 2011), sobretudo em solos urbanos de ambientes em regeneração.

As aranhas (Araneae) são um grupo importante da macrofauna. Predadoras, regulam as populações de nichos inferiores, além de serem consideradas como indicadoras de qualidade ambiental, uma vez que indicam o grau de intervenção antrópica do ambiente e alterações do microclima (BARETTA et al., 2007). Warui et al. (2005) sugerem que a diversidade da cobertura vegetal e o tipo de cobertura do solo podem influenciar a composição e riqueza de comunidades de aranhas. A qualidade de serrapilheira e diversidade de plantas vivas (BRENNAN et al.,2006) também podem influenciar na composição da comunidade.

Os besouros (Coleoptera), a exemplo das famílias Scarabeidae e Staphylinidae, têm importantes atribuições ecológicas, como o hábito escavatório que provoca o revolvimento de solo, decomposição e transporte de material orgânico e a reciclagem de nutrientes e o hábito saprófago e fitófago, que colaboram com a redução de dejetos e resíduos de origem animal e vegetal, facilitando a decomposição e acúmulo de matéria orgânica (HORGAN, 2001; BARETTA et al., 2006). As atribuições ecológicas desenvolveram sua fisiologia mandibular, que é composta por um aparelho bucal mastigador bem desenvolvido. Além disso, são invertebrados sensíveis às mudanças ambientais, podendo assim ser utilizados como indicadores de qualidade (NICHOLS et al., 2008).

Os atributos químicos do solo como $\mathrm{pH}, \mathrm{K}, \mathrm{P}, \mathrm{Ca}, \mathrm{Mg}, \mathrm{Al}$ e $\mathrm{C} . \mathrm{O}$ são considerados variáveis ambientais explicativas que influenciam nas modificações dos grupos de fauna, a depender da estação do ano e características do ambiente. Essas propriedades interferem na adaptação, dispersão, distribuição e estabelecimento de famílias e morfo-espécies e, portanto, na riqueza e diversidade dos organismos (ROSA et al., 2015). De forma geral, pesquisas demonstram que a maioria dos grupos de fauna edáfica tem correlação positiva com o tipo de manejo do solo, com terrores de $\mathrm{K}, \mathrm{P}, \mathrm{Ca}, \mathrm{Mg}, \mathrm{Al}$ e com o teor de C.O do ambiente independente da época de amostragem (SILVA et al., 2006; PORTILHO et al., 2011; ROSA et al., 2015). 
Os fragmentos florestais analisados tem em seu histórico de manejo e ocupação o plantio de café e captação de água fluvial, eventos ocorridos principalmente no século 19 (PLANO DE MANEJO DO PARQUE CANTAREIRA, 2009). São áreas que passaram por vastos períodos de intervenção antrópica e que hoje se encontram em estágio de regeneração. A avaliação atual desses fragmentos apresenta uma importância ambiental fundamental no contexto urbano uma vez que eles colaboram diretamente com a preservação da biodiversidade e dos serviços ecossistêmicos. A conservação das matas nativas localizadas nos grandes conglomerados auxilia no regime de regulação hídrica, preservação de nascentes e da biodiversidade animal e vegetal, manutenção da qualidade de solo, polinização, porosidade dos solos, ciclagem de nutrientes nos solos, regulação térmica, dispersão de sementes, sequestro de carbono, na formação de solos e na minimização dos efeitos nocivos da poluição do ar (BARBOSA et al.,2002).

O levantamento de espécies e famílias de fauna edáfica adaptadas em ambientes com características não mais originais é uma ferramenta de grande importância para a adoção de critérios de avaliação que qualifiquem os processos ecossistêmicos recorrentes nos fragmentos urbanos em regeneração, especificamente os parques Cantareira, Jaraguá e Cientec (Complexo pertencente ao Parque Fontes do Ipiranga), evidenciando a importância do presente estudo que teve como objetivo avaliar a biodiversidade e a qualidade de solos localizados em fragmentos florestais urbanos da cidade de São Paulo.

\section{Materiais e método}

Buscou-se por fragmentos florestais urbanos que tivessem o histórico semelhante de manejo, cobertura vegetal, classes de solos e altimetria, se apresentando, portanto, como réplica verdadeira dos ambientes $(\mathrm{n}=$ 3). A preocupação com áreas correlatas se deu na busca de promover melhores correlações entre os parâmetros ambientais, químicos e biológicos avaliados nos três parques, sendo eles: Cantareira, Jaraguá e Cientec (Complexo pertencente ao Parque Fontes do Ipiranga).

Utilizando o modelo de classificação climática de W. Köppen (1923), baseada na temperatura e precipitação média mensal e anual dos ambientes, o clima é do tipo Cwb, ou seja, clima temperado com estações anuais bem definidas, regimes de chuvas no verão e inverno seco e temperaturas variando de $18^{\circ} \mathrm{C}$ a $22{ }^{\circ} \mathrm{C}$. Essas características marcam uma realidade climática de transição, principalmente pela intercalação entre longos períodos muito secos ou úmidos e variações bruscas de tempo seguidas de intensa precipitação, fenômenos explicados pela influência da máxima oscilação sul, El Ninõ (MONTEIRO, 1973).Os fragmentos florestais estudados apresentam cobertura de matas secundárias em estado de regeneração. No período que vai do início do século XIX até a década de 30 do século XX, em seu histórico de manejo, as áreas sofreram pressões antrópicas provenientes da economia cafeeira e de projetos públicos envolvendo a busca por adução de água potável (BARBOSA et al., 2002; PLANO DE MANEJO DO PARQUE CANTAREIRA, 2009; PLANO DE MANJEO DO PARQUE JARAGUÁ, 2010).

Para a confecção da parcela amostral delimitou-se sobre os três parques as seguintes etapas de atividade de campo: (a) Foram instaladas aleatoriamente duas parcelas de área fixa (1, 68 ha) por parque; (b) A demarcação foi estabelecida no planalto, em cotas altimétricas entre $780 \mathrm{~m}$ e $860 \mathrm{~m}$ e em dois ambientes físicos diferentes, próximo ao curso central de drenagem (canais de drenagem naturais e áreas alagadiças) e em áreas secas com serapilheira; (c) As coletas ocorreram de forma concentrada no verão (02/2014) e inverno (09/2014); (e) Em todos ambientes (seco e úmido) foram amostrados 18 pontos de coleta, totalizando 216 armadilhas; (f) As armadilhas foram instaladas, a 30 metros de distância frontal e lateral, respeitando área de bordadura de $20 \mathrm{~m}$, para evitar a autocorrelação entre os pontos; (g) Todos os pontos de amostragem foram geo - referenciados (GPS) para posteriormente gerarem uma matriz de dados digitais.

A liberação das licenças de coleta nos três parques ocorreu via cadastramento e avaliação do projeto pelo Sistema de Autorização e Informação de Biodiversidade (SISBIO) do Ministério do Meio Ambiente (MMA) processo $n^{\circ}$ 42474-2 e pela Secretaria do Meio Ambiente (SMA) e Instituto Florestal (IF) do estado de São Paulo processo $\mathrm{n}^{\circ} 260108-000.204 / 2014$. Após análise e concordância dos órgãos ambientais federais e estaduais, as espécies e morfo-espécies de aranhas (Araneae) e besouros (Coleoptera) foram coletadas.

Utilizou-se na coleta armadilhas de queda ou "pitfall-traps", construídos com garrafa PET, apresentando aberturas com dimensões de $6 \times 4 \mathrm{~cm}$. As aberturas estavam localizadas a $20 \mathrm{~cm}$ da base da garrafa (ANTONIOLLI, 2006). As armadilhas foram enterradas com as aberturas no nível do solo, para facilitar a entrada da entomofauna. Cada armadilha continha a solução de $200 \mathrm{ml}$ de uma mistura de água e duas gotas de detergente neutro a 2,5\% (FREITAS et al., 2004) sendo mantidas nas parcelas por 5 dias. Foram coletadas 108 amostras de solo utilizando os procedimentos de coleta segundo manual de métodos de análises e procedimentos da Empresa Brasileira de Pesquisa Agropecuária (EMBRAPA, 2011), a fim de se averiguar os teores de fósforo $(\mathrm{P})$, potássio $(\mathrm{K})$, magnésio $(\mathrm{Mg})$, cálcio $(\mathrm{Ca})$, alumínio $(\mathrm{Al})$, carbono orgânico $(\mathrm{C} . \mathrm{O})$ e 
acidez $(\mathrm{pH})$. As amostras foram analisadas no Laboratório de Solos da Escola Superior de Agronomia Luiz de Queiroz - ESALQ/USP.

Posteriormente, colocaram-se os espécimes coletados em uma bandeja e, cuidadosamente, com a ajuda de uma pinça, os exemplares da biota foram repassados para um recipiente plástico devidamente identificado contendo álcool 92\% (FREITAS et al., 2004). As aranhas foram encaminhadas para o Instituto Butantã e os besouros para o Museu de Zoologia da Universidade de São Paulo. As observações gerais para avaliação da taxonomia foram realizadas com auxílio de microscópio estereoscópio (lupa) com aumento de até 40 vezes, enquanto que as estruturas mais particulares necessitaram de um microscópio óptico com aumento de até 100 vezes. Os organismos foram separados e agrupados pelos táxons e por grandes grupos. Quando possível, foram identificados ao nível de famílias, tribos ou espécies com auxílio de chaves dicotômicas e/ou caracterizações contidas na literatura taxonômica (BRESCOVIT et al., 2007; CASARI \& IDE, 2012). Para todos os indivíduos que não puderam ser identificados ao nível de espécie foram atribuídos indicadores morfológicos temporários ("sp 1") devido a incertezas na nomenclatura, e dessa forma, os mesmos serão apresentados como morfo-espécies.

A diversidade foi expressa pelo índice de diversidade de Shannon $(\mathrm{H})\left[\mathrm{H}=-\sum\right.$ (pi log pi), onde pi $=\mathrm{ni} / \mathrm{N}$; ni = densidade de cada família , $\mathrm{N}=$ número total de famílias] e pela riqueza de famílias, de acordo com Odum (1983). Por fim, antes da análise estatística multivariada, os dados (sem outliers) foram transformados $(\sqrt{ } \mathrm{x}+1)$, quando necessário, para atender as exigências da análise de variância (ANOVA; distribuição normal e homocedasticidade de variâncias de erro). ANOVA de efeitos principais foi utilizada para comparar a abundância, riqueza e índide de Shannon $(\mathrm{H})$ entre os diferentes ambientes, usando Software Statistica 7.0 (StatSoft, 2004). Médias apresentadas foram calculadas utilizando dados não transformadas ( \pm desvio padrão). Os dados de abundância foram submetidos a uma Detrended Correspondence Analysis (DCA), a fim de obter o comprimento do gradiente. Considerando que este comprimento foi inferior a três $(<3)$, com resposta linear, optou-se por fazer a Principal Component Analysis (PCA), e quando superior a três (> 3), com resposta unimodal, optou-se por fazer Correspondence Analysis (CA).

A abundância de cada grupo foi utilizada como variável resposta e os atributos químicos do solo como variáveis ambientais explicativas nas PCAs ou CAs. As variáveis explicativas colineares foram identificadas através do Variance Inflation Factor (VIF), e por operações de forward selection, usando sucessivas Redundancy Analysis (RDA) ou Canonical Correspondence Analysis (CCA) com base em permutações por teste de Monte-Carlo para cada tipo de variável, retirando as que apresentaram colinearidade e selecionando as que melhor explicaram a variação dos dados $(\mathrm{p} \leq 0,05)$, permitindo a escolha de um conjunto mínimo de variáveis ambientais significativas para explicar a variação dos grupos de Araneae e Coleoptera em cada época e ambiente de coleta. Somente as variáveis significativas das RDAs/CCAs foram posteriormente utilizadas nas PCAs/CCAs como variáveis ambientais explicativas passivas para as mudanças observadas em grupos de Araneae e Coleoptera. Para todas essas análises estatísticas multivariadas utilizou-se o software estatístico CANOCO versão 4.5 (TER BRAAK e ŠMILAUER, 2002)

\section{Resultados e Discussões}

A presença ou ausência das diferentes famílias de aranhas em fragmentos de Mata Atlântica em regeneração, obtidas pelo método Pitfall-Trap, considerando todas as áreas, estações e ambientes, totalizou 208 exemplares distribuídos em 33 morfo-espécies de 16 famílias diferentes (Tabela 1). As coletas indicam que a abundância de araneae (espécimes por armadilha) apresentaram no verão 78 indivíduos em ambiente úmido e $56 \mathrm{em}$ ambiente seco e no inverno 29 indivíduos em ambiente úmido e $45 \mathrm{em}$ ambiente seco. As coletas indicam que a redução de indivíduos coletados no verão em relação aos coletados no inverno foi de $45 \%$. Entre as famílias registradas, a maior abundância se deu para as famílias Miturgidae (48\%) e Corinnidae (26\%) no verão e Ctenidae $(6 \%)$ e Pholcidae (4\%) no inverno, enquanto que a menor abundância de coleópteros se deu majoritariamente no inverno. Apenas estas quatro famílias compuseram $85 \%$ do total de aranhas coletadas. 
Tabela 1: Parâmetros da fauna de aranhas do solo em ambiente seco e úmido de fragmentos florestais urbanos coletados pelo método do Pitfall-Trap

\begin{tabular}{|c|c|c|c|c|c|c|c|c|c|}
\hline \multirow{2}{*}{ Família } & \multirow{2}{*}{ Gênero/Espécie } & \multicolumn{2}{|c|}{ Inverno } & \multicolumn{2}{|c|}{$\%$ de inverno } & \multicolumn{2}{|c|}{ Verão } & \multicolumn{2}{|c|}{ \% verão } \\
\hline & & Seco & Úmido & Seco & Úmido & Seco & Úmido & Seco & Úmido \\
\hline \multirow{6}{*}{$\begin{array}{l}\text { Araneidae } \\
\text { Corinnidae }\end{array}$} & & 1 & - & 2.2 & - & 2 & - & 3.5 & - \\
\hline & & - & - & - & - & - & 3 & - & 3.8 \\
\hline & Castianeira sp.1 & 1 & - & 2.2 & - & - & - & - & - \\
\hline & Corinna sp. 1 & 7 & 1 & 15.5 & 3.4 & 1 & 4 & 1.7 & 5.1 \\
\hline & Ianduba varia & 1 & 9 & 2.2 & 31 & 7 & 20 & 12.5 & 25.6 \\
\hline & Tupirinna sp.1 & - & 1 & - & 3.4 & - & - & - & - \\
\hline \multirow[t]{3}{*}{ Ctenidae } & & 2 & 4 & 4.3 & 13.7 & 1 & 3 & 1.7 & 3.8 \\
\hline & $\begin{array}{l}\text { Enoploctenus } \\
\text { cyclothorax }\end{array}$ & - & - & - & - & - & 2 & - & 2.5 \\
\hline & $\begin{array}{l}\text { Isoctenus } \\
\text { coxalis }\end{array}$ & - & 1 & - & 3.4 & - & - & - & - \\
\hline Gnaphosidae & Zimiromus sp.1 & - & - & - & - & - & 1 & - & 1.2 \\
\hline Hahniidae & Neohahnia sp.1 & 1 & - & 2.2 & - & - & - & - & - \\
\hline \multirow[t]{2}{*}{ Idiopidae } & & 1 & - & 2.2 & - & - & - & - & - \\
\hline & Idiops sp. 1 & - & 1 & - & 3.4 & - & - & - & - \\
\hline Linyphiidae & Mermessus sp.1 & - & - & - & - & - & 1 & - & 1.2 \\
\hline \multirow[t]{3}{*}{ Miturgidae } & & - & 2 & - & 6.8 & - & - & - & - \\
\hline & Odo sp.1 & 14 & 2 & 31 & 6.8 & 4 & 14 & 7.1 & 17.9 \\
\hline & Odo sp.2 & 8 & - & 17 & - & 32 & 24 & 57 & 30.7 \\
\hline \multirow[t]{3}{*}{ Nemesiidae } & Rachias sp.1 & 1 & 1 & 2.2 & 3.4 & - & 1 & - & 1.2 \\
\hline & $\begin{array}{l}\text { Stenoterommata } \\
\text { sp. } 1\end{array}$ & - & - & - & - & - & 2 & - & 2.4 \\
\hline & $\begin{array}{l}\text { Stenoterommata } \\
\text { sp. } 2\end{array}$ & - & 1 & - & 3.4 & - & - & - & - \\
\hline Oonopidae & Scaphiella sp.1 & - & - & - & - & 1 & - & 1.7 & - \\
\hline \multirow[t]{2}{*}{ Pholcidae } & & - & - & - & - & 1 & - & 1.7 & - \\
\hline & $\begin{array}{l}\text { Mesabolivar } \\
\text { forceps }\end{array}$ & 4 & 3 & 8.8 & 10.3 & - & - & - & - \\
\hline \multirow[t]{2}{*}{ Salticidae } & Corythalia sp.1 & - & - & - & - & 2 & 2 & 3.4 & 2.4 \\
\hline & Corythalia sp.2 & - & 1 & - & 3.4 & - & - & - & - \\
\hline Scytodidae & Scytodes fusca & - & 1 & - & 3.4 & 1 & - & 1.7 & - \\
\hline \multirow[t]{2}{*}{ Tetragnathidae } & & - & - & - & - & 1 & - & 1.7 & - \\
\hline & Azilia sp.1 & - & - & - & - & 1 & - & 1.7 & - \\
\hline \multirow[t]{2}{*}{ Theridiidae } & & - & 1 & - & 3.4 & - & - & - & - \\
\hline & Guaraniella sp.1 & 1 & - & 2.2 & - & - & - & - & - \\
\hline \multirow[t]{3}{*}{ Zodariidae } & & - & - & - & - & - & 1 & - & 1.2 \\
\hline & Tenedos sp.1 & 2 & - & 4.3 & - & 2 & - & 3.4 & - \\
\hline & Tenedos sp.2 & 2 & - & 4.3 & - & - & - & - & - \\
\hline \multicolumn{2}{|c|}{ Número Total de Espécimes m-2 } & 45 & 29 & $100 \%$ & $100 \%$ & 56 & 78 & $100 \%$ & $100 \%$ \\
\hline \multicolumn{2}{|c|}{ Desvio Padrão $( \pm)$} & $\begin{array}{c}15.0 \\
\pm \\
6.7\end{array}$ & $\begin{array}{c}9.7 \pm \\
3.0\end{array}$ & & & $\begin{array}{c}18.7 \\
\pm 12.0\end{array}$ & $\begin{array}{c}26.0 \pm \\
9.8\end{array}$ & & \\
\hline \multicolumn{2}{|c|}{ Riqueza Total de Famílias } & 13 & 14 & & & 13 & 13 & & \\
\hline \multicolumn{2}{|c|}{ Desvio Padrão $( \pm)$} & $\begin{array}{c}5.3 \\
\pm \\
2.2\end{array}$ & $\begin{array}{c}5.3 \pm \\
1.9\end{array}$ & & & $\begin{array}{l}5.0 \pm \\
2.1\end{array}$ & $\begin{array}{c}5.3 \pm \\
0.9\end{array}$ & & \\
\hline \multicolumn{2}{|c|}{$\begin{array}{l}\text { Índice de Diversidade de Shannon } \\
\text { (H)_Desvio Padrão }( \pm)\end{array}$} & $\begin{array}{c}1.10 \\
\pm \\
0.55\end{array}$ & $\begin{array}{c}1.43 \pm \\
0.32\end{array}$ & & & $\begin{array}{c}0.95 \\
\pm \\
0.13\end{array}$ & $\begin{array}{c}1.20 \pm \\
0.08\end{array}$ & & \\
\hline
\end{tabular}


O índice de diversidade de Shannon $(\mathrm{H})$ apresenta os menores índices $\mathrm{H}$ no ambiente úmido e seco do verão e os maiores índices $\mathrm{H}$ para os ambientes úmido e seco do inverno, o que significa que a diversidade e a riqueza de espécimes estão respondendo às alterações microclimáticas e edafo-ambientais. $\mathrm{O}$ indicador $\mathrm{H}$ frequentemente é reportado como um indicativo de diferenciação entre os ambientes (ODUM,1983), o que pode ser observado pela diferença nos valores entre os ambientes e entre as estações do ano. Porém, um problema na interpretação nos valores de diversidade pode ocorrer, pois, em algumas circunstâncias, o valor de $\mathrm{H}$ pode aumentar após moderada perturbação (SCOTT et al., 2006). No caso de família de aranhas, o $\mathrm{H}$ ainda pode mudar rapidamente de uma estação ou de um ambiente para outro, especialmente durante o período de acasalamento (aranhas são mais ativas), em que famílias de aranhas são mais abundantes (SCOTT et al., 2006). Alguns autores sugerem ainda que a diversidade dos tipos de coberturas florestais pode influenciar na riqueza da comunidade de aranhas (WARUI et al., 2005 ; BRENNAN et al., 2006, BARETTA et al., 2007).

As famílias Miturgidae e Corinnidae, também conhecidas como caçadoras, foram as mais frequentes nas coletas, apresentando reduções significativas em ambiente úmido e no inverno. A família Miturgidae, com 74 exemplares no verão e 26 no inverno, apresentou uma queda de $65 \%$ no volume total coletado na estação de inverno. A família Corinnidae totalizou 35 exemplares no verão e 20 no inverno, que representa uma redução de $43 \%$. A família Ctenidae com 7 no inverno e 6 no verão indica aumento de $17 \%$ no inverno. A família Pholcidae com 7 no inverno e 1 no verão, apresenta aumento de $600 \%$ no inverno. Quando se discute os dados em relação à alternância de ambientes (seco e úmido), tem-se que a família Miturgidae apresentou 58 indivíduos coletados em ambiente seco e 42 em ambiente úmido, o que representa uma redução de $28 \%$ no ambiente úmido. A família Pholcidae obteve 5 indivíduos em ambiente seco e $3 \mathrm{em}$ ambiente úmido, indicando uma redução de $40 \%$. A família Ctenidae apresentou 10 indivíduos em ambiente úmido e 3 em ambiente seco e sofreu aumento de $233 \%$ no ambiente úmido. Por fim, a família Corinnidae totalizou 38 em ambiente úmido e 17 indivíduos no ambiente seco, totalizando um aumento de 124\%. Observa-se que as famílias Miturgidae e Pholcidae estiveram mais adaptadas ao verão e ambiente seco enquanto que a família Ctenidae esteve mais adaptada ao inverno e ambiente úmido e Corinnidae ao verão e ambiente úmido.

Entre as famílias registradas, Corinnidae foi a família que apresentou o maior riqueza de morfo-espécies (5), seguida por Ctenidae (3), Miturgidae (3) e Pholcidae (2). Essas quatro famílias, com Nemesiidae e Zodariidae foram responsáveis por $52 \%$ (19) da riqueza total. As famílias Miturgidae e Corinnidae apresentaram maior riqueza no verão, porém esta em ambiente seco e aquela em ambiente úmido. As famílias Pholcidae e Ctenidae apresentaram maior riqueza no inverno, porém esta em ambiente seco, e aquela em ambiente úmido. Avaliando-se o histórico das áreas, ao realizar trabalhos de campo e também ao conversar com a administração dos parques é possível notar que as áreas experimentaram e ainda vivenciam questões vinculadas à pressão antrópica. Os baixos valores ou ausência de famílias construtoras de teias (Theridiidae, Araneidae, Tetragnathidae e Linyphiidae) nos fragmentos florestais estudados, indicam de que as áreas realmente passaram por períodos de perturbação (BARETTA et al., 2007).

As análises de componentes principais (ACP), para as espécies de aranhas amostradas tanto no inverno (Figura 1A) quanto no verão (Figura 1B) demonstraram separação entre os ambientes úmido e seco. Esta análise também nos permite visualizar a maior ou menor associação entre cada família de aranha com as variáveis edafo-ambientais estudadas, onde quanto mais próximo a família das variáveis, maior a interação entre ambos e a ocorrência conjunta. Ao observar o resultado da ACP para o inverno (Figura 1A), a variabilidade dos dados explicada pelo eixo 1 foi de $28.9 \%$ e no eixo 2 de $24.1 \%$. Houve distinção entre os ambientes que ficaram em lados opostos no gráfico, onde as espécies de aranhas ficaram mais distribuídas no ambiente seco. As espécies Idio, Guar sp. 1, Neoh sp. 1, Tene sp. 1, Cori sp. 1, Mesa rce, Odo sp. 1, Idio sp. 1 , isoc xal, Scyt fus, Sten sp. 2, obtiveram maior interação com o ambiente seco, resultado que pode ser explicado pela decomposição da serrapilheira e consequentemente teores elevados de carbono orgânico do solo (OC) nesse ambiente. Já as espécies de aranhas Cten, Mitu, Tupi sp. 1, Iand var, Cast sp. 1, Odo sp. 2, Tene sp. 2, Cory sp. 2, Ther, ficaram mais relacionadas ao ambiente úmido e Al. 
A

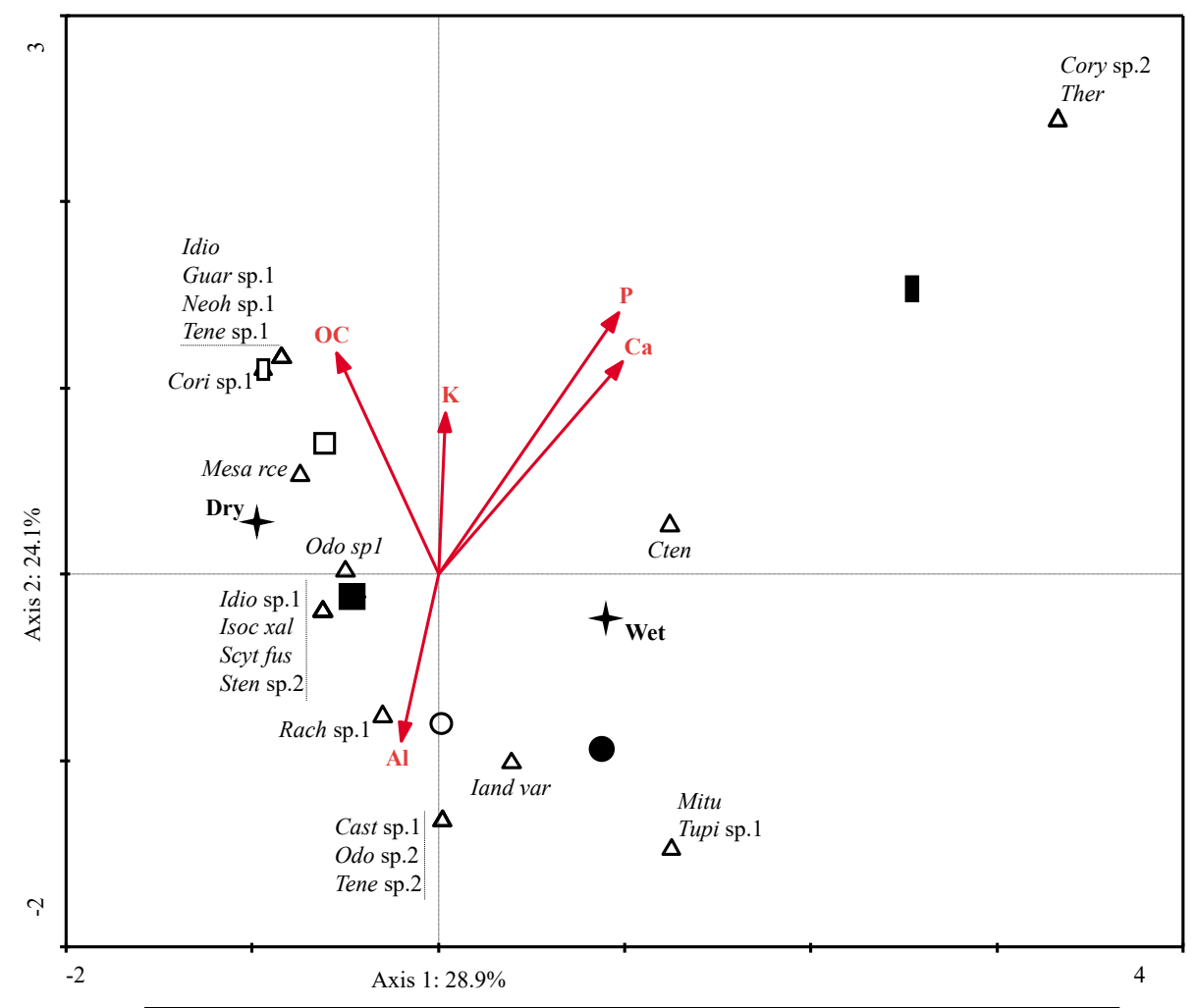

B

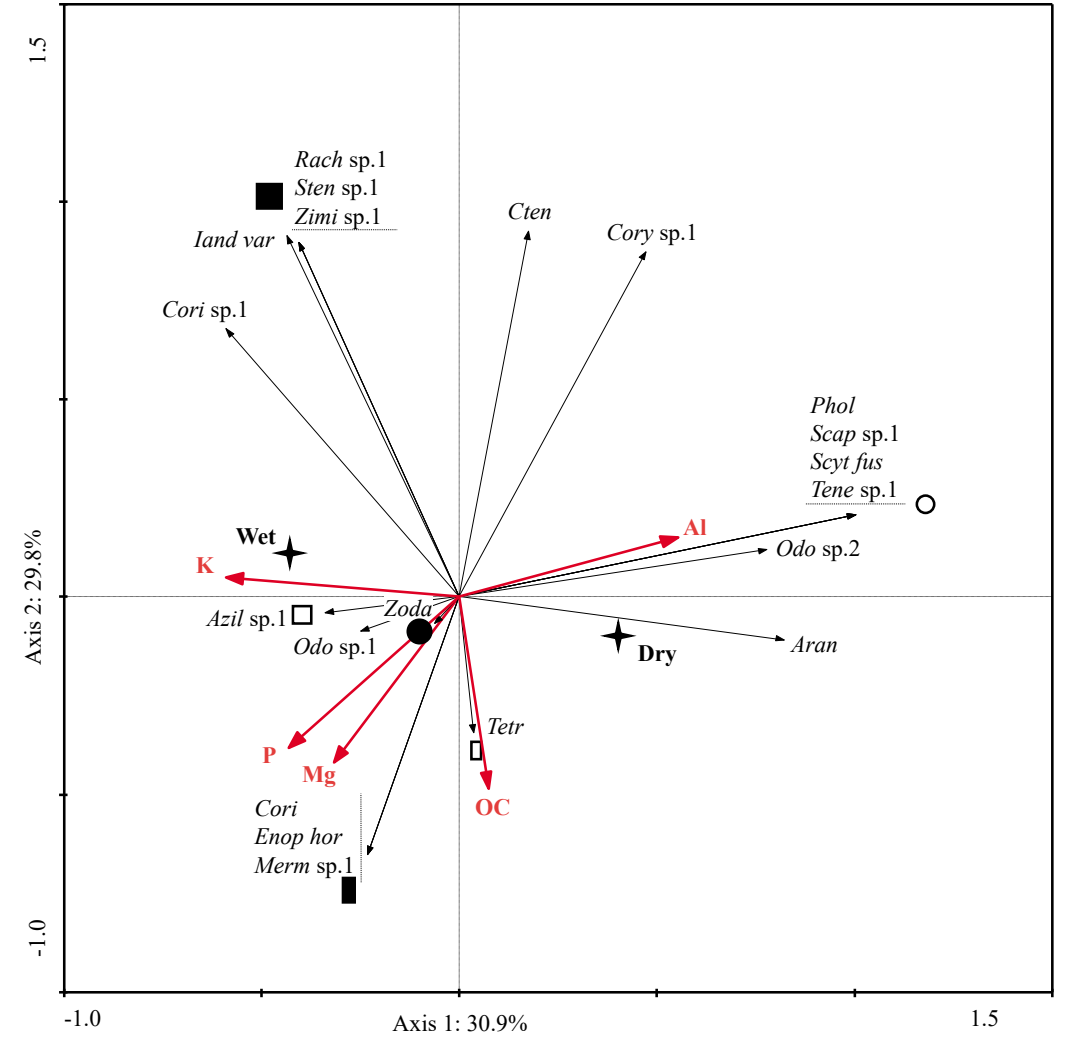

Figura 1: Análise de componentes principais (ACP) das aranhas (itálico), em relação ao ambiente seco ou úmido (preto) de fragmentos florestais urbanos da cidade de São Paulo, SP, no inverno (A) e verão (B), e as variáveis ambientais (vermelho) utilizadas como explicativas. Símbolos brancos correspondem ao ambiente seco e símbolos pretos ao ambiente úmido. Estrela: centroide dos três fragmentos florestais. Círculo: Cientec; Quadrado: Cantareira; Retângulo: Jaraguá. Al: alumínio; Ca: cálcio; K: potássio; Mg: magnésio; OC: carbono orgânico; P: fosforo e $\mathrm{pH}$. 
No verão (Figura 1B) o resultado da $\mathrm{ACP}$, demonstra que no eixo 1 a variação dos dados foi de $30.9 \% \mathrm{e}$ no eixo 2 de $29.8 \%$. O ambiente úmido teve maior relação com as espécies de aranhas que o ambiente seco. Percebe-se que as variáveis ambientais tiveram maior relação com as espécies do que no inverno, onde $\mathrm{K}, \mathrm{P}$ e Mg tiveram maior importância no ambiente úmido e carbono orgânico (OC) e Al no ambiente seco, sendo as que mais contribuíram para explicar a distribuição das espécies. No ambiente úmido, a espécie Azil sp. 1 teve maior associação com o K, enquanto Zoda e Odo sp. 1 com o P. Já as espécies Cori, Enop hor e Mem sp.1 apresentaram maior associação com o Mg. Além das espécies Cori sp. 1, Iand var, Rach sp. 1, Sten sp. 1 e Zimi sp. 1, todos sem associação evidente com as variáveis ambientas. No ambiente seco, a espécie Tetr apresentou forte associação com o teor de OC, enquanto as espécies Aran, Odo sp. 2, Phol, Scap sp. 1, Scyt fus, Tene sp. 1 ficaram mais associadas ao Al. As espécies Cten e Cory sp. 1, ambas sem associação evidente com o ambiente.

Considerando todas as áreas, estações e ambientes, foram capturados 454 besouros, distribuídos em 76 morfo-espécies de 14 famílias diferentes (Tabela 2). As coletas indicam que a abundância de coleópteros (espécimes por armadilha) apresentou um número total maior no verão, em ambiente seco (158) e ambiente úmido (97) e menor no inverno, em ambiente seco (67) e ambiente úmido (131). A redução de 255 indivíduos coletados no verão para 198 indivíduos coletados no inverno foi de $22 \%$. Entre as famílias registradas, a maior abundância se deu para as famílias Staphylinidae (43\%), Scarabaeidae (13\%) e Carabidae (10\%) no verão e Nitidulidae (17\%) no inverno, enquanto que a menor abundância de coleópteros se deu majoritariamente no inverno. Apenas estas quatro famílias compuseram $83 \%$ do total de besouros coletados.

Tabela 2. Famílias e Morfo-espécies de coleópteros do solo em ambiente seco e úmido de fragmentos florestais urbanos coletados pelo método Pitfall-Trap

\begin{tabular}{|c|c|c|c|c|c|c|c|c|c|}
\hline \multirow{2}{*}{ Família } & \multirow{2}{*}{ Gênero/Espécie } & \multicolumn{2}{|c|}{ Inverno } & \multicolumn{2}{|c|}{ \% Inverno } & \multicolumn{2}{|c|}{ Verão } & \multicolumn{2}{|c|}{ \% Verão } \\
\hline & & Seco & Úmido & Seco & Úmido & Seco & Úmido & Seco & Úmido \\
\hline \multirow[t]{6}{*}{ Carabidae } & Carabidae sp. 1 & 2 & 1 & 3,0 & 0,8 & - & 1 & - & 1,0 \\
\hline & Carabidae sp. 2 & - & - & - & - & - & 1 & - & 1,0 \\
\hline & Carabidae sp. 3 & - & - & - & - & 6 & - & 3,8 & - \\
\hline & Carabidae sp. 4 & - & - & - & - & 2 & - & 1,3 & - \\
\hline & Carabidae sp. 5 & - & 2 & - & 1,5 & 1 & 2 & 0,6 & 2,1 \\
\hline & Cincidelinae sp. 1 & - & - & - & - & 18 & 10 & 11,4 & 10,3 \\
\hline \multirow[t]{4}{*}{ Chrysomelidae } & Chrysomelidae sp. 1 & - & 1 & - & 0,8 & - & - & - & - \\
\hline & Chrysomelidae sp. 2 & - & 1 & - & 0,8 & - & - & - & - \\
\hline & Chrysomelidae sp. 3 & 1 & 1 & 1,5 & 0,8 & - & - & - & - \\
\hline & Chrysomelidae sp. 4 & 1 & - & 1,5 & - & - & - & - & - \\
\hline Coccinelidae & Coccinelidae sp. 1 & - & - & - & - & - & 1 & - & 1,0 \\
\hline \multirow[t]{5}{*}{ Curculionidae } & Curculionidae sp. 1 & 1 & - & 1,5 & - & - & - & - & - \\
\hline & Curculionidae sp. 2 & - & 1 & - & 0,8 & - & - & - & - \\
\hline & Curculionidae sp. 3 & - & 1 & - & 0,8 & - & - & - & - \\
\hline & Scolytinae sp. 1 & 1 & - & 1,5 & - & - & - & - & - \\
\hline & Scolytinae sp. 2 & - & 2 & - & 1,5 & - & - & - & - \\
\hline Elateridae & Elateridae sp. 1 & - & - & - & - & - & 1 & - & 1,0 \\
\hline Endomychidae & Endomychidae sp. 1 & - & - & - & - & 1 & - & 0,6 & - \\
\hline \multirow[t]{3}{*}{ Histeridae } & Histeridae sp. 1 & - & - & - & - & 2 & 3 & 1,3 & 3,1 \\
\hline & Histeridae sp. 2 & - & - & - & - & 1 & - & 0,6 & - \\
\hline & Histeridae sp. 3 & - & 1 & - & 0,8 & - & - & - & - \\
\hline \multirow[t]{3}{*}{ Hydrophylidae } & Sphaeridiinae sp. 1 & - & - & - & - & 4 & 1 & 2,5 & 1,0 \\
\hline & Sphaeridiinae sp. 2 & 2 & 1 & 3,0 & 0,8 & - & - & - & - \\
\hline & Sphaeridiinae sp. 3 & - & 1 & - & 0,8 & - & 3 & - & 3,1 \\
\hline \multirow[t]{2}{*}{ Leiodidae } & Leiodidae sp. 1 & 4 & 16 & 6,0 & 12,1 & - & - & - & - \\
\hline & Leiodidae sp. 2 & 1 & 6 & 1,5 & 4,5 & - & 1 & - & 1,0 \\
\hline Mycetophagidae & Mycetophagidae sp. 1 & - & 3 & - & 2,3 & - & - & - & - \\
\hline \multirow[t]{2}{*}{ Nitidulidae } & Brachypeplus sp. 1 & - & - & - & - & 1 & - & 0,6 & - \\
\hline & Brachypeplus sp. 2 & - & 3 & - & 2,3 & - & - & - & - \\
\hline
\end{tabular}


Continuação Tabela 2

Colopterus sp. 1

Lobiopa insularis

Nitidulidae sp. 1

Stelidota sp. 1

Stelidota sp. 2

Stelidota sp. 3

Stelidota sp. 4

Scarabaeidae

Ateuchus sp. 1

Ateuchus sp. 2

Cathidium sp. 1

Cathidium sp. 2

Dichotomius sp. 1

Dichotomius sp. 2

Dichotomius sp. 3

Dichotomius sp. 4

Paracanthon sp. 1

Sylvicanthon sp. 1

Uroxys sp. 1

Staphylinidae Staphylinidae sp. 1

Staphylinidae sp. 2

Staphylinidae sp. 3

Staphylinidae sp. 4

Staphylinidae sp. 5

Staphylinidae sp. 6

Staphylinidae sp. 7

Staphylinidae sp. 8

Staphylinidae sp. 9

Staphylinidae sp. 10

Staphylinidae sp. 11

Staphylinidae sp. 12

Staphylinidae sp. 13

Staphylinidae sp. 14

Staphylinidae sp. 15

Staphylinidae sp. 16

Staphylinidae sp. 17

Staphylinidae sp. 18

Staphylinidae sp. 19

Staphylinidae sp. 20

Staphylinidae sp. 21

Staphylinidae sp. 22

Staphylinidae sp. 23

9

13,4

$1,5 \quad 0,8$

1

$26 \quad 23$

1,5

$38,8 \quad 17,4$

$3,0 \quad 0,8$

1,5

0,8

0,8

1,0

-

$\begin{array}{lll}- & 13 & 11\end{array}$

$8,2 \quad 11,3$

$\begin{array}{lll}- & - & 1\end{array}$

1,0

18

$11,4 \quad 6,2$

0,8

$$
0,6
$$

1,5

0,6

- $\quad 1,0$

- 1,0

0,6

2,5

1,0

3,0

1,3

1,0

15,2

1,3

0,6

-

-

1,0

0,8

3,8

12,4

3,8

10,8

11,3

32

4,5

1,5

6,3

4,1

2,3

0,6

0,8

$14,6 \quad 2,1$

1,5

7,2

3,8

$\begin{array}{ll}6,3 & 7,2 \\ 0,6 & 1,0\end{array}$

Tenebrionidae sp. 1

Tenebrionidae sp. 2

Tenebrionidae sp. 3

Tenebrionidae sp. 4

Tenebrionidae sp. 5

Tenebrionidae sp. 6

Número Total de Espécimes $\mathbf{m}^{-2}$

Desvio Padrão $( \pm)$

Riqueza Total de Famílias

Desvio Padrão ( \pm )

Índice de Diversidade de Shannon (H)

Desvio Padrão $( \pm)$

$\mathrm{m}^{-2}$

67

$22.3 \pm 43.7 \pm$

$12.3 \quad 25.6$

$22 \quad 38$

$8.7 \pm \quad 15.0 \pm$

$2.4 \quad 6.7$

$1.75 \pm 2.04 \pm$

$0.25 \quad 0.49$

1,5
1,5

-

0,6

$3,2 \quad 1,0$

- $\quad 0,8$

$6,0 \quad 1,5$

1,5

0,8

- -

1,5

1,5

0,8

0,8

$0,6 \quad 2,1$

-

0,6

1,0

1,0

3,0

$100 \% \quad 100 \%$

158

97

$100 \% \quad 100 \%$

$52.7 \pm 32.3 \pm$

$15.2 \quad 11.8$

$30 \quad 32$

$14.3 \pm 14.7 \pm$

$1.9 \quad 3.3$

$2.19 \pm 2.33 \pm$

$0.08 \quad 0.22$ 
$\mathrm{O}$ índice de diversidade de Shannon $(\mathrm{H})$ apresenta os maiores índices $\mathrm{H}$ no ambiente úmido e seco do verão e os menores índices para os ambientes úmido e seco do inverno, o que significa que a diversidade e a riqueza de espécimes estão respondendo às alterações microclimáticas e edafo-ambientais. É possível ainda observar a tendência de que a estação do verão está favorecendo a manutenção das famílias de coleópteros.

A família Sthaphylinidae, com 128 exemplares no verão e 69 no inverno, apresentou uma queda de $46 \%$ no volume total coletado na estação de inverno. A família Scarabaeidae totalizou 56 exemplares no verão e 4 no inverno, apresentando redução de 93\%. A família Carabidae com 41 exemplares no verão e 5 no inverno, indica redução de $88 \%$. Somente a família Nitidulidae com 9 exemplares coletados no verão e 70 no inverno, apresenta aumento de $678 \%$ no volume total coletado no verão. Os dados avaliando a adaptação das famílias com a presença ou ausência de canal de drenagem na parcela amostral demonstram que a família Sthaphylinidae apresentou um aumento de 3\% de indivíduos coletados em ambiente úmido. Já as famílias Scarabaeidae e Carabidae obtiveram uma redução de $18 \%$ e $41 \%$ de exemplares em ambiente úmido, respectivamente. Por fim, a família Nitidulidae totalizou uma redução de 16\% em ambiente úmido. Observase que as famílias Sthaphylinidae esteve mais adaptada ao verão nos dois ambientes, as famílias Scarabaeidae e Carabidae estiveram mais adaptadas ao verão em ambiente seco e por fim, a família Nitidulidae esteve mais adaptada ao inverno também no ambiente seco.

Entre as famílias registradas, Staphylinidae foi a família que apresentou a maior riqueza de morfoespécies (23), seguido por Scarabaeidae (11) Nitidulidae (9) e Carabidae (6). Essas quatro famílias, com Chrysomelidae, Curculionidae e Tenebrionidae foram responsáveis por $84 \%$ (64) da riqueza total. As famílias Scarabaeidae e Carabidae apresentaram maior riqueza no verão em ambiente seco. A família Nitidulidae apresentou maior riqueza no inverno no ambiente úmido e a família Staphylinidae apresentou maior riqueza no verão em ambos ambientes. Tanto a abundância como a riqueza de Staphylinidae está associada à sua grande diversidade, o que faz com que sejam encontrados em quase todos os tipos de ecossistemas (FAGUNDES et al., 2011).

Das principais famílias amostradas, apenas a família Carabidae tem hábito exclusivamente carnívoro, enquanto que as demais apresentam hábitos variados. A família Staphylinidae apresenta hábito carnívoro, detritívoro ou fungívoro, a família Nitidulidae apresenta hábito carnívoro, detritívoro, fungívoro e herbívoro e por fim, a família Scarabaeidae que apresenta hábito herbívoro ou detritívoro (PORTILHO et al., 2011, SILVA, 2011 ; POMPEO et al., 2016). Três famílias apresentam hábitos detritívoros o que significa que elas auxiliam o fluxo de entrada de nutrientes no solo decompondo matéria orgânica estando, portanto, adaptadas em locais com vegetação densa e solos com serrapilheira, características comuns das parcelas amostrais. Essa correlação explica maior conexão das famílias com o ambiente seco.

A abundância, diversidade, riqueza e hábito das famílias de coleópteros encontrados majoritariamente em ambientes secos e no verão, podem estar associados à variação da composição (quantidade e qualidade) de serrapilheira, elevada disponibilidade de recursos alimentares e quantidade de plantas vivas e cobertura vegetal. Estas características incentivam as populações de besouros de hábitos variados, que também são responsáveis pela ciclagem de nutrientes, decomposição da matéria orgânica, redistribuição de material orgânico e mineral e dispersão de sementes (FAGUNDES et al., 2011). A menor adaptação às diferenças de exposição solar, microclima do solo e respostas dos fenômenos meteorológicos externos podem explicar os decréscimos ocorridos em ambiente úmido e inverno. Com exceção para a família Nitidulidae que apresentou maior abundância e riqueza no inverno devido à plasticidade e diferentes hábitos de suas espécies, que podem se adaptar aos mais variados tipos de ecossistemas e dieta alimentar (AUDINO et al., 2007). Isso significa que tendências observadas também respondem à dinâmica das comunidades.

As análises de componentes principais (ACP), para as espécies de coleópteros amostrados tanto no inverno (Figura 2A) quanto no verão (Figura 2B) demonstraram separação entre os ambientes úmido e seco.

Ao observar o resultado da ACP para o inverno (Figura 2A), a variabilidade dos dados explicada pelo eixo 1 foi de $29.5 \%$ e no eixo $220.2 \%$. Houve distinção entre os ambientes que ficaram em lados opostos no gráfico, onde as morfo-espécies de coleópteros ficaram distribuídas entre os ambientes. As inseridas no círculo pontilhado obtiveram maior interação com o ambiente seco, relação que pode ser explicada, para a maioria das espécies, ou seja, as que estão mais próximas da variável, pela maior relação desse ambiente com os teores de carbono orgânico do solo. Já no ambiente úmido, as espécies envolvidas no círculo contínuo, ficaram mais relacionadas ao ambiente úmido associadas às variáveis $\mathrm{pH}$ " $\mathrm{H} 2 \mathrm{O}$ " e " $\mathrm{K}$ ". 

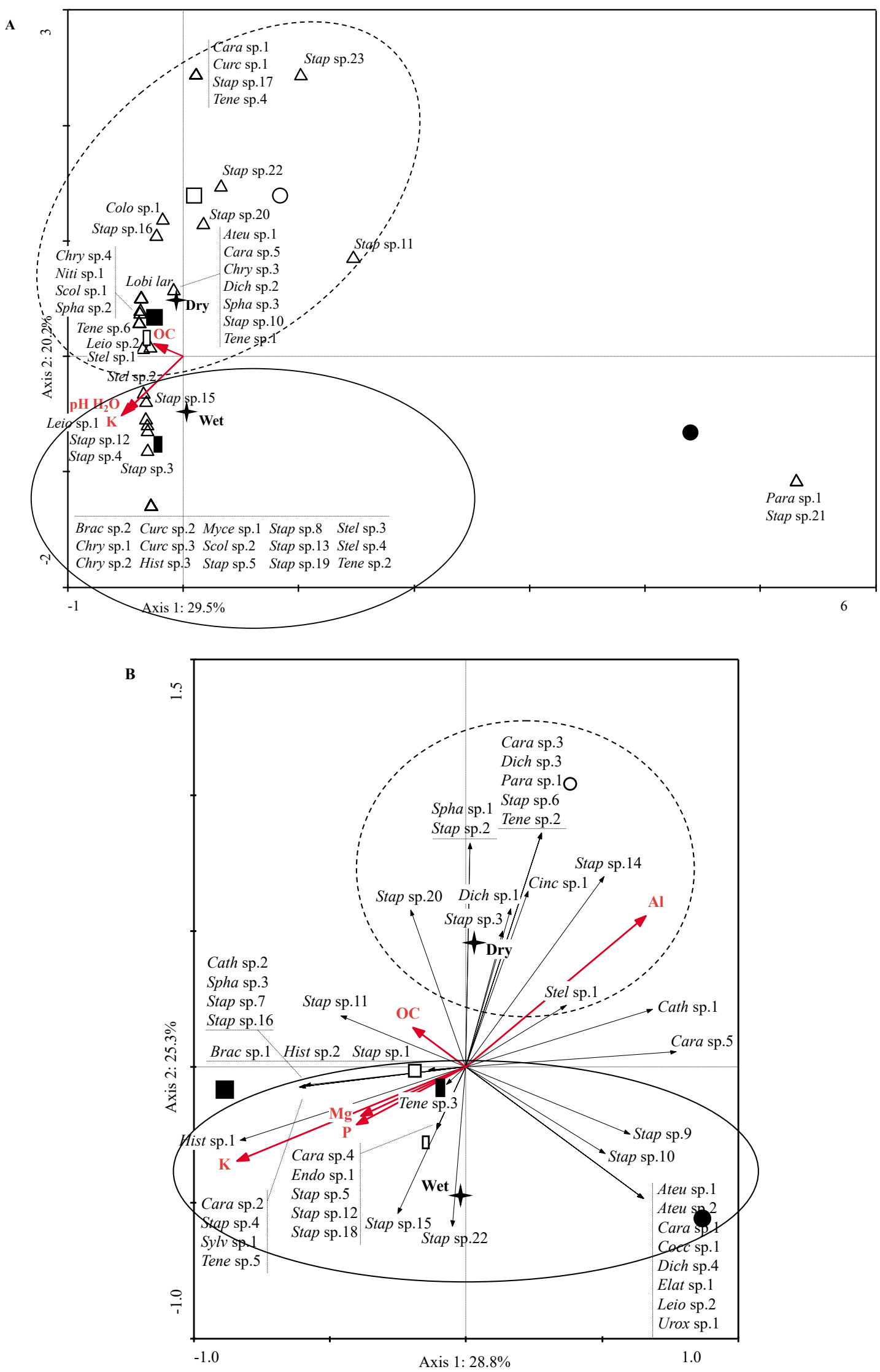

Figura 2: Análise de componentes principais dos coleópteros (itálico), em relação ao ambiente seco ou úmido (preto) de fragmentos florestais urbanos da cidade de São Paulo, SP, no inverno (A) e verão (B), e as variáveis ambientais (vermelho) utilizadas como explicativas. Símbolos brancos correspondem ao ambiente seco e símbolos pretos ao ambiente úmido. Estrela: centroide dos três fragmentos florestais. Círculo: Cientec; Quadrado: Cantareira; Retângulo: Jaraguá. Al: alumínio; K: potássio; Mg: magnésio; OC: carbono orgânico; P: fosforo e pH. 
No verão (Figura 2B) o resultado da $\mathrm{ACP}$, demonstra que no eixo 1 a variação dos dados foi de $28.8 \%$ e no eixo 2 de $25.3 \%$. Novamente, as morfo-espécies de coleópteros ficaram distribuídas entre os ambientes. O ambiente úmido teve maior relação com as espécies de coleópteros envolvidas no círculo contínuo e o ambiente seco pelas espécies envolvidas no círculo pontilhado. Percebe-se que as variáveis ambientais tiveram maior relação com as espécies no ambiente úmido, onde $\mathrm{K}, \mathrm{P}$ e $\mathrm{Mg}$ tiveram maior importância, e $\mathrm{Al}$ no ambiente seco, sendo as que mais contribuíram para explicar a distribuição das espécies.

O aumento e diminuição da ocorrência de algumas famílias e morfo-espécies de araneae e coleópteros frente à alteração de ambiente (secos e úmidos) e as estações do ano, estão relacionados à grande sensibilidade da maior parte das espécies às condições microclimáticas (NUNES et al., 2009; SIMPSON et al., 2012), principalmente ao que se refere à influência da umidade do solo (HOLMSTRUP et al., 2012). Variações de temperatura e umidade ao longo das estações do ano são fatores que influenciam a densidade, diversidade, riqueza e abundância da fauna edáfica (FERNANDES et al., 2011). Merlim et al. (2005) verificaram que as características químicas e físicas do solo, aliadas às condições climáticas, contribuíram para as alterações na densidade e na diversidade da comunidade de larvas de coleópteros do solo em ecossistemas de Araucária angustifólia. Geissen e Guzman (2006) relatam que o carbono orgânico (C.O) e a acidez do solo foram os atributos que tiveram maior influência sobre a densidade e a diversidade da biota edáfica, enquanto que Baretta et al. (2011) apontam que a diversidade tem relação direta com a elevada concentração de carbono orgânico (C.O). Lavelle et al. (1995) citam que alguns organismos podem se adaptar a diferentes condições de acidez, o que explica frequências elevadas de indivíduos em ambientes extremamente ácidos. Todas essas correlações apresentaram-se como positivas no presente inventário indicando a influência dos atributos edafo-ambientais e do manejo, na riqueza, diversidade e abundância das famílias e morfo-espécies estudadas, assim como os organismos como indicadores ecológicos sensíveis de intervenção humana em fragmentos florestais de Mata Atlântica.

\section{Considerações finais}

Os resultados obtidos permitem deduzir que os indivíduos da ordem araneae e coleoptera coletados nos parques urbanos avaliados, são sensíveis indicadores de mudanças edafo-ambientais em áreas com fragmentos florestais urbanos. As conclusões adicionais que podem ser feitas a partir desse estudo são:

- A riqueza e diversidade dos organismos coletados foram influenciadas por parâmetros químicos do solo e alternância de ambientes e estações do ano, sendo estes fatores limitantes para a sua ocorrência, frequência e estabelecimento. Constata-se que, dentre todas as variáveis edafo-ambientais analisadas, o microclima, a qualidade e quantidade de serrapilheira, a cobertura vegetal, elevadas taxas de carbono orgânico (C.O), biodisponibilidade de macronutrientes $(\mathrm{P}, \mathrm{K}, \mathrm{Ca}$ e $\mathrm{Mg})$ e $\mathrm{pH}$, foram as que preservaram interação com as famílias e morfo-espécies capturadas.

- A diversidade, riqueza e o índice de diversidade de Shanon $(\mathrm{H})$ dos organismos coletados são afetados por variações microclimáticas como umidade e temperatura, tipo e estrutura da cobertura vegetal, qualidade da serapilheira, C.O e macronutrientes. A análise de componentes principais (ACP) se mostrou como ferramenta essencial em estudos pedo-ecológicos, pois demonstrou que existe separação entre os ambientes estudados e quais foram as famílias e morfo-espécies que mais se associaram com cada variável analisada.

- A utilização aranhas e besouros como bioindicadores corroborou para o monitoramento da biodiversidade e qualidade de solos localizados em fragmentos de Mata Atlântica urbanos que apresentam em seu histórico atividades ligadas à perturbação ambiental ocasionada por práticas antrópicas. $\mathrm{O}$ uso de organismos indicadores é eficaz, pois demonstra sua vulnerabilidade quanto ás mudanças nos ecossistemas. Seu emprego demonstra as mudanças nos ambientes e responde às alterações ambientais explicadas por sua correlação com processos que ocorrerem nos solos.

\section{REFERÊNCIAS}

AUDINO, L.D.; NOGUEIRA, J.M.; SILVA, P.G.; NESKE, M.Z.; RAMOS, A.H.B.; MORAES, L.P.; BORBA, M.F.S. Identificação dos coleópteros Insecta: Coleoptera das regiões de Palmas município de Bagé e Santa Barbinha município de Caçapava do Sul, RS. Bagé: Embrapa Pecuária Sul, 2007.92 p.

ANTONIOLLI, I.Z.; CONCEIÇÃO, P.C.; BOCK, V.; PORT, O.; SILVA, D.M.; SILVA, R.F. Método alternativo para estudar a fauna do solo. Ciência Florestal, Santa Maria, v. 16, n. 4, p. 407- 417, 2006.

BARBOSA, L.M.; POTOMATI, A.; PECCINI, A.A. O Pefí: histórico e Legislação. In: BICUDO, D.C.; FORTI, M.C.; BICUDO, C.E.M. (Orgs.). Parque Estadual das Fontes do Ipiranga (PEFI): unidade de conservação que 
resiste à urbanização de São Paulo. São Paulo: Editora Secretaria do Meio Ambiente do Estado de São Paulo, p. 15-28, 2002.

BARETTA, D.; MAFRA, A.L.; SANTOS, J.C.P.; AMARANTE, C.V.T \& BERTOL, I. Análise multivariada da fauna edáfica em diferentes sistemas de preparo e cultivo do solo. Pesquisa Agropecuária Brasileira,v. 41, p.1675-1679, 2006.

BARETTA, D.; BRESCOVIT, A.D.; KNYSAK, I \& CARDOSO, E.J.B.N. Trap and soil monolith sampled edaphic spiders (arachnida;aranae) in Araucaria angustifolis forest. Scientia Agrícola, v.64, p. 375-383, 2007.

BARETTA, D.; BROWN, G.C.; CARDOSO, E.J.B.N. Potencial da macrofauna e outras variáveis edáficas como indicadores de qualidade do solo em áreas com Araucaria angustifólia. Acta Zoológica Mexicana, v.2, p. 135-150, 2010.

BARETTA, D.; SANTOS, J.C.P.; SEGAT, J.C.; GEREMIA, E.V.; FILHO, L.C.I.O.; ALVES, M.V. Fauna edáfica e qualidade do solo. In: KLAUBERG FILHO, O.; MAFRA, A.L.; GATIBONI, L.C.(Orgs.). Tópicos em ciência do solo. Viçosa: Sociedade brasileira de ciência do solo, v.7, p. 141-192, 2011.

BEARE, M.H.; COLEMAN, D.C.; CROSSLEY JR., D.A; HENDRIX, P.F.; ODUM, E.P. A hierarchical approach to evaluating the significance of soil biodiversity to biogeochemical cycling. Plant and Soil, Hague, v.170, p. 5-22, 1995.

BRENNAN, K. C. E.; ASHBY, L.; MAJER, J. D.; MOIR, M. L.; KOCH, J. M. Simplifying assessment of forest management practices for invertebrates: How effective are higher taxon and habitat surrogates for spiders following prescribed burning ? Forest Ecology and Management, Amsterdam, v.231, p.138-154, 2006.

BRESCOVIT, A. D.; RHEIMS, C. A; BONALDO, A. B (Orgs.). Chave de identificação para famílias de aranhas brasileiras. Instituto Butantan, 2007.

CASARI, S.A e IDE, S. Coleopteras. In: ALBERTINO et al. (Orgs.). Insetos do Brasil: Diversidade e Taxonomia. Ribeirão Preto. Holos Editora, 2012. p.454-535.

DARWIN, C. R. The Formation of Vegetable Mould through the Action of Worms with Observations on Their Habits. 6th thousand (corrected) London: John Murray, 1881, 328p.

EMBRAPA - Empresa Brasileira de Pesquisa Agropecuária. Centro Nacional de Pesquisas de Solos. Manual de métodos de análises de solos. 2.ed. Rio de Janeiro: Embrapa Solos, 2011. 230p.

FAGUNDES, C.K.; DI MARE, R.A; WINK, C.; MANFIO, D. Diversity of the families of Coleoptera captured with pitfall traps in five different environments in Santa Maria, RS, Brazil. Brazilian Journal of Biology, v. 71, n. 2, p. 381-390, 2011.

FERNANDES, M.M.; MAGALHÃES, L.M.S.; PEREIRA, M.G.; CORREIA, M.E.F.; BRITO, R.J. \& MOURA, M.R. Influência de diferentes coberturas florestais na fauna do solo na Flona Mário Xavier, no município de Seropédica, RJ. Floresta, v.41, p.533-540, 2011.

FREITAS, A. V. L.; FRANCINI, R. B.; BROWN JR, K. S. Insetos como indicadores ambientais. In: CULLEN JR., L. et al (eds). Métodos de estudo em biologia da conservação e manejo da vida. Curitiba: UFPR. p. 125$151,2004$.

GEISSEN, V., GUZMAN, G. M. Fertility of tropical soils under different land use systems-a case study of soils in Tabasco, México. Applied Soil Ecology, v.31, p.169-178, 2006.

HOLMSTRUP, M.; SORENSEN, J.G.; MARALDO, K.; SCHMIDT, I.K.; MASON, S.; TIETEMAD, A.; SMITH, A.R.; EMMETT, B.; SCHMELZ, R.M.; BATAILLON, T.; BEIER, C. \& EHLERS, B. K. Increased frequency of drought reduces species richness of enchytraeid communities in both wet and dry heathland soils. Soil Biology Biochemistry., v.53, p.43-49, 2012.

HORGAN, F.G. Burial of bovine dung by coprophagous Beetles (Coleoptera: Scarabaeidae) from house and cow grazing sites in El Salvador. European Journal Soil Biology., v.47, p.103-111, 2001.

JAMES, S., BARTZ, M.L.C., BROWN, G.G. Curso de Ecologia e Taxonomia de Minhocas. Curitiba: Embrapa Florestas, Universidade Positivo, Universidade Federal do Paraná, 2015. (Apostila).

KÖPPEN, W. Die Klimate der Erde. Berlin: W Guyter, 1923. 369p.

LAVElle, P., CHAUVEL, A., FRAGOSO, C. Faunal activity in acid soils. In: DARE, R.A. et al (eds) Plant Soil Interactions at Low pH. Kluwer Academic Publishers: Netherlands. p. 201-211, 1995.

LAVElle, P.; DECAENS, T.; AUBERT, M.; BAROT, S.; BlOUIN, M.; BUREAU, F.; MARGERIE, P.; MORA, P. e ROSSI, J.P. Soil Invertebrates and ecosystem services. European. Journal of Soil Biology, v.42, p. $3-15,2006$. 
LAVELLE, P e PASHANASI, B. Soil macrofauna and land management in Peruvian Amazonia ( Yurimanguas, Loreto) Pedobiologia, v. 33, p. 283-291, 1989.

MELO-JÚNIOR, H. B. M. Estruturas Biogênicas em latossolos de chapadões. Uberlândia, Universidade Federal de Uberlândia. 2012. 31p. (Dissertação de mestrado).

MERLIM, A.O.; GUERRA, J.G.M.; JUNQUEIRA, R.M.; AQUINO, A.M. Soil macrofauna in cover crops of figs grown under organic management. Scientia Agricola, v.62, p.57-61, 2005.

MONTEIRO, C. A. de F. A dinâmica climática e as chuvas no Estado de São Paulo: estudo geográfico sob a forma de atlas. São Paulo, Instituto de Geografia da Universidade de São Paulo, 1973, 129p.

NICHOLS, E.; SPECTOR, S.; LOUZADA, J.; LARSEN, T.; AMEZQUITA, S.; FAVILA, M.E. Ecological functions and ecosystem services provided by Escarabeinae dung beetles. Biological Conservation, v.141, n.6, p. 1461-1474, 2008.

NUNES, L.A.P.L.; ARAÚJO FILHO, J.A. de; MENEZES, R.I. de Q. Diversidade da fauna edáfica em solos submetidos a diferentes sistemas de manejo no semi-árido nordestino. Scientia Agraria, v.10, p.43-49, 2009.

ODUM, E. P. Ecologia. Rio de Janeiro: Guanabara, 1983.434p.

POMPEO, P.N.; OLIVEIRA FILHO, L.C.I.; FILHO, O.K.; MAFRA, A.L.; BARETTA, C.R.D.M.; BARETTA, D. Diversidade de Coleoptera (Arthropoda: Insecta) e atributos edáficos em sistemas de uso do solo no Planalto Catarinense. Revista Scientia Agraria, Curitiba, v.17, n.1, p.16-28, 2016.

PORTILHO, I. I. R.; CREPALDI, R. A.; BORGES, C. D.; SILVA, R. F. da; SALTON, J. C.; MERCANTE, F. M. Fauna invertebrada e atributos físicos e químicos do solo em sistemas de integração lavoura-pecuária. Pesquisa Agropecuária Brasileira. v. 46, n. 10, p. 1310-1320, 2011.

ROSA, M. G.; KLAUBERG, O. F.; BARTZ, M.L.C.; MAFRA, A.L.; SOUSA, J.P.F.A.; BARETTA, D. Macrofauna edáfica e atributos físicos e químicos em sistemas de uso do solo no Planalto Catarinense. Revista Brasileira de Ciência do Solo, v. 39, p. 1544-1553, 2015.

SCOTT, A. G.; OXFORD, G. S.; SELDEN, P. A. Epigeic spiders as ecological indicators of conservation value of peat bogs. Biological Conservation, Essex, v.127, p.420-428, 2006.

SIMPSON, J. E.; SLADE, E.; RIUTTA, T. \& TAYLOR, M. E. Factors affecting soil fauna feeding activity in a fragmented lowland temperate deciduous woodland. PLOS ONE, v.7, p.1-6, 2012.

SILVA, A. J. N, CABEDA, M. S. V, CARVALHO, F. G. Matéria orgânica e propriedades físicas de um Argissolo Amarelo coeso sob sistemas de manejo com cana-de-açúcar. Revista Brasileira Engenharia Agrícola Ambiental, v. 10, p. 579-85, 2006.

SILVA, P.G. Espécies de escarabaeinae (coleoptera : escarabaidae) de fragmentos florestais com diferentes níveis de alteração em Santa Maria, Rio Grande do Sul. Santa Maria, Universidade Federal de Santa Maria, 2011. 167p. (Dissertação de Mestrado).

SMA/Fundação Florestal/Instituto Florestal, Plano de Manejo do Parque Estadual da Cantareira. São Paulo: Fundação Florestal do Estado de São Paulo. 2009.

SMA/Fundação Florestal/Instituto Florestal, Plano de Manejo do Parque Estadual do Jaraguá. São Paulo: Fundação Florestal do Estado de São Paulo. 2010.

STATSOFT, Inc. 2004. STATISTICA (data analysis software system), version 7. www.statsoft.com.

TER BRAAK, C. J. F. \& SMILAUER, P. CANOCO reference manual and CanoDraw for Windows: software for canonical community ordination (version 4.5). Microcomputer Power, Ithaca. 2002.

VEZZANI, F.M e MIELNICZUK, J. Revisão de literatura: uma visão sobre qualidade do solo. Revista Brasileira de Ciência do Solo, v.33, p. 743-755, 2009.

WARUI, C. M; VILLET, M. H; YOUNG, T. P; JOCQUE, R. Influence of grazing by large mammals on the spider community of a Kenyan savanna biome. Journal of Arachnology, Lubbock, v.33, p.269-279, 2005. 